\title{
Hybrid Control using Adaptive Particle Swarm Optimization and Integral Backstepping Control of Grid-connected Doubly Fed Induction Generator
}

\author{
EImostafa Chetouani*, Youssef Errami, Abdellatif Obbadi and Smail Sahnoun \\ Laboratory, Electronics, Instrumentation and Energy, Exploitation and Processing of Renewable Energy, \\ Department of Physics, Faculty of Sciences, University of Chouaib Doukkali, El Jadida, Morocco
}

('Corresponding author's e-mail: chetouani.m@ucd.ac.ma)

Received: 26 February 2021, Revised: 6 June 2021, Accepted: 9 June 2021

\begin{abstract}
We proposed an analysis of a hybrid control of active and reactive power for a doubly-fed induction generator for variable velocity wind energy injection into the electrical grid using a combination of adaptive particle swarm optimization and integral backstepping control in this paper. The stability of the Lyapunov function is utilized to establish the latter. Six controllers are developed as part of the proposed control process: The first is concerned with the maximum PowerPoint. The stator powers are managed by the second and third regulators, which are performed by the optimal PI controller using adaptive particle swarm optimization. The DC link voltage is kept constant by the fourth controller. The fifth and sixth are employed to pilot the rotor powers and ensure that the power factor is maintained to 1 . These three controllers are synthesized by using the nonlinear integral backstepping control. These control strategies show excellent results compared to field-oriented control under a variable wind speed profile and changing generator settings in a Matlab/Simulink environment. According to the test findings, using integral backstepping, the overshoot of the DC-link voltage is decreased by $99.16 \%$. Furthermore, the particle swarm optimization reduces its time to reach the equilibrium state to $4.3 \mathrm{~m} \mathrm{~s}$ and demonstrates robustness against parameter generator changes.
\end{abstract}

Keywords: Doubly fed induction generator, Indirect vector control, Integral backstepping control, Particle swarm optimization, Proportional-integral controller, Wind energy system

\section{Introduction}

Wind energy is one of the most interesting and encouraging sources of renewable energy globally, principally because it minimizes the environmental pollution caused by traditional power plants and the dependence on fossil fuels, which remain expensive sources and have limited stocks.

Wind turbines with high output power in the megawatt range use a variety of generator technologies, including permanent magnet synchronous generators (PMSG), squirrel cage induction generators (SCIG), and doubly-fed induction generators (DFIG) [1]. Wind energy conversion system (WECS) incorporated the DFIG is becoming a popular configuration due to several advantages. For example, it can operate at low and high speeds. It can be used in a partial-sized converter in the rotor to control power, reduce power losses and cost, reduce mechanical parts' efforts, reduce noise, control the active and reactive power, and a controllable power factor [2]. The DFIG stator is directly branched to the grid. However, two bidirectional converters connect the rotor to the electrical network via a DC-link voltage, as shown in Figure 1. The rotor side converter (RSC) is used to control stator powers exchanged with the grid. Also, the RSC ensures the regulation of the power factor to 1 . Nevertheless, the grid side converter (GSC) is employed to maintain the DC-link voltage invariant [3]. Its complex and nonlinear mathematical equations characterize the induction machine model. The active and reactive power control independently is not a simple task because the input variables are strongly coupled [4]. Currently, many control schemes have been invoked to control the DFIG destined for the wind chain to reach high performances. Besides, some techniques permit the conversion of a nonlinear system model into a linear model. Ihedrane et al. [4] have established the sliding mode control and non-adaptive Backstepping control to study the system stability without analytically solving the nonlinear mathematical equations. The authors have tested the performance of the two methods. Likewise, Elmahfoud et al. [5] have 
compared and have applied the rotor field-oriented control and the adaptive backstepping strategy to the doubly-fed inductor motor. The robustness tests of the proposed control are checked by varying the motor parameters. Besides, Elghamrasni et al. [6] have proposed a comparison study of nonlinear sliding mode control (SMC) and Backstepping Control (BSC) for controlling the rotor side and grid side converters. The authors have shown that the BSC presents robustness and linearization of the WECS based on the DFIG against the SMC. Furthermore, Djeriri [7] has proposed a Backstepping approach to control the RSC of the DFIG to decouple and control the stator active and reactive power. The robustness is tested by variation of the DFIG parameters, and the wind speed value is fixed. Besides, Benakcha et al. [8] have replaced the PI controller with the backstepping controller. In addition to these control approaches, direct torque control (DTC) has been proposed to control the induction generator's electromagnetic torque and the stator flux separately. The authors in [9] have developed and implemented DTC for an induction machine using space vector modulation on a DSP hardware circuit. The authors show the effectiveness of the proposed method in terms of reducing ripples and improving response time. Recently, new optimization techniques (fuzzy logic, neural network, particle swarm optimization algorithm, etc.) have been advised by a number of researchers to control the DFIG and to deal with the primary drawbacks of indirect vector control based on the PI controllers, that gain values are dependent on the generator parameters. Cherifi and Miloud [10] have proposed a hybrid control based on the fuzzy logic and sliding mode method to control the RSC of the DFIG. Besides, Rached et al. [11] have proposed fuzzy logic to control the active and reactive power of the DFIG. The presence of oscillations in the transient regime may be seen in the simulation results. Furthermore, fuzzy logic has several drawbacks, such as the difficulty of precisely specifying the fuzzy laws and membership functions. The verification of a fuzzy knowledge-based system necessitates considerable hardware testing. However, because the FLC is not always correct, the results are based on assumptions, making it difficult to accept [12]. A particle swarm optimization (PSO) is one of the widely used artificial intelligence algorithms. The PSO has been broadly utilized to control the powers of the DFIG. This control approach reduces calculation time, maintains high precision, is resistant to system fluctuation factors, and can be implemented in a low-cost microcontroller [13]. The authors [14] have applied PSO to enhance the performances of the PI controllers. The latter is applied to control the rotor side converter. A comparative study between the proposed controller and the conventional PI controller has been offered. In [15], a comparison analysis between PSO and SMC has been offered. The author compares PSO-PISMC, PSO-ISMC, and the conventional PSOSMC to show that the PSO-PISMC presents a faster transient response and an improved tracking error for a wind turbine system. The authors [16] have examined the problem of the overshoot of the stator and rotor currents in the case of grid perturbation. They have proposed the PSO algorithm to tune the parameters of PID controllers for reducing the high value of the currents to protect the back-to-back converters.

The extractable power from wind energy depends on the characteristics of each turbine and the wind variable speed. Consequently, tracking the maximum power point is required in the normal operation of the turbine. This strategy is known as the maximum power point (MPP) algorithm. Several schemes are developed to perform this algorithm. In this work, we design the MPP using the optimal tip speed ratio (OPTSR), which is established on the PI controller.

Figure 1 shows the most widely used WECS configuration, which is adopted in this work and implemented in matlab/simulink environment.

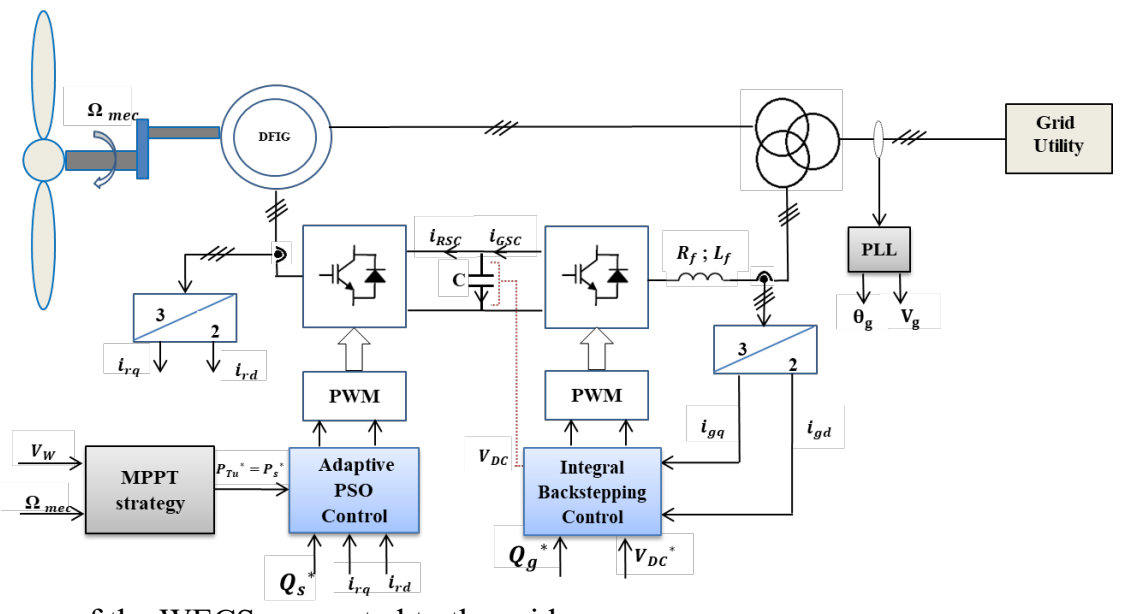

Figure 1 Scheme of the WECS connected to the grid. 


\section{Materials and methods}

\section{Wind energy system modeling}

\section{Wind turbine modeling}

The produced aerodynamic power of the wind turbine is given by [17]:

$\mathrm{P}_{\text {mech }}=\mathrm{P}_{\mathrm{Tu}}=\frac{1}{2} \cdot \mathrm{C}_{\mathrm{P}}(\lambda, \beta) \cdot \rho \cdot \pi \cdot \mathrm{R}^{2} \cdot \mathrm{V}_{\mathrm{w}}{ }^{3}$

Where $\rho$ is the air density $\left(\mathrm{kg} / \mathrm{m}^{3}\right), \mathrm{V}_{\mathrm{w}}$ is the wind speed (in $\left.\mathrm{m} / \mathrm{s}\right), \mathrm{R}$ is the blade radius (m), and $\mathrm{C}_{\mathrm{P}}$ is the performance coefficient of the turbine, which is expressed by [18]:

$C_{P}(\lambda, \beta)=[0.5-0.0167 .(\beta-2)] \cdot \sin \left(\frac{\pi(\lambda+0.1)}{18.5-0.3 \cdot(\beta-2)}\right)-0.00184 .(\lambda-3) \cdot(\beta-2)$

Where $(\beta)$ is the wind turbine pitch angle and $(\lambda)$ is the tip speed ratio given as [17].

The tip-speed ratio $\lambda$ equation is given as follows $[17,18]$ :

$\lambda=\frac{\mathrm{R} \cdot \Omega_{\mathrm{Tu}}}{\mathrm{V}}$

The mechanical equation of the system is given by $[17,19]$ :

$\mathrm{J}_{\text {tot }} \cdot \frac{\mathrm{d} \Omega_{\mathrm{mec}}}{\mathrm{dt}}+\mathrm{f} \cdot \Omega_{\mathrm{mec}}=\mathrm{T}_{\mathrm{g}}-\mathrm{T}_{\mathrm{em}}$

Where $\mathrm{J}_{\text {tot }}$ is the overall inertia of wind energy conversion system, $\mathrm{T}_{\mathrm{Tu}}$ is the turbine torque, $\mathrm{T}_{\mathrm{Tem}}$ is the electromagnetic torque of the DFIG, $T_{g}$ is the gearbox torque, $f$ is the overall viscous coefficient of friction, $\Omega_{\text {mec }}$ is the gearbox mechanical speed ( $\left.\mathrm{rad} / \mathrm{s}\right)$, and $\mathrm{G}_{\mathrm{B}}$ is the gearbox multiplier.

\section{DFIG modeling}

The stator and rotor voltages and field magnetic flux equations can be developed in the d-q park frame reference as follows [19]:

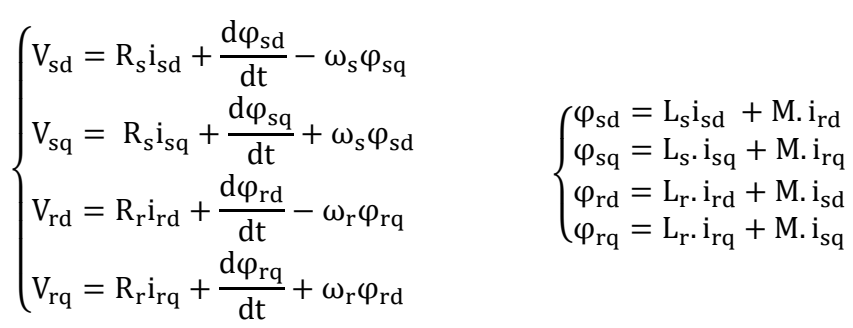

Where $V_{s}$ and $V_{r}$ are the stator and rotor voltage, $i_{s}$ and $i_{r}$ are the stator and the rotor current, $\varphi_{s}$ and $\varphi_{r}$ are the stator and the rotor flux linkages, $R_{s}$ and $R_{r}$ are the stator and the rotor resistances, $L_{s}, L_{r}$ and $M$ is the stator, rotor and magnetizing inductances, respectively.

The electromagnetic torque can be given by [19]:

$\mathrm{T}_{\mathrm{em}}=-\mathrm{p} \cdot \frac{\mathrm{M}}{\mathrm{L}_{\mathrm{s}}}\left(\mathrm{i}_{\mathrm{rq}} \varphi_{\mathrm{sd}}-\mathrm{i}_{\mathrm{rd}} \varphi_{\mathrm{sq}}\right)$

Where $\mathrm{p}$ is the number of DFIG pole pairs.

The stator and rotor active and reactive powers are expressed as follows as [19]:

$\mathrm{P}_{\mathrm{s}}=\mathrm{V}_{\mathrm{sd}} \cdot \mathrm{i}_{\mathrm{sd}}+\mathrm{V}_{\mathrm{sq}} \cdot \mathrm{i}_{\mathrm{sq}}$

$\mathrm{Q}_{\mathrm{s}}=\mathrm{V}_{\mathrm{sd}} \cdot \mathrm{i}_{\mathrm{sd}}-\mathrm{V}_{\mathrm{sd}} \cdot \mathrm{i}_{\mathrm{sq}}$ 
It assumed that the stator magnetic field-oriented control is according to d-axis. The grid voltage is computed by the phase-locked loop (PLL) strategy. We hypothesize that the voltage across the stator resistance is neglected compared to stator terminal voltages [17-19]:

$\varphi_{\mathrm{sd}}=\varphi_{\mathrm{s}}, \quad \varphi_{\mathrm{sq}}=0$

$\mathrm{V}_{\mathrm{sd}}=0, \quad \mathrm{~V}_{\mathrm{sq}}=\mathrm{V}_{\mathrm{s}}=\mathrm{w}_{\mathrm{s}} \cdot \varphi_{\mathrm{s}}$

The rotor voltages can be expressed as follows [20]:

$V_{r d}=\left[R_{r}+\left(L_{r}-\frac{M^{2}}{L_{s}}\right) \cdot s\right] i_{r d}-g \cdot \omega_{s}\left(L_{r}-\frac{M^{2}}{L_{s}}\right) i_{r q}$

$V_{r q}=\left[R_{r}+\left(L_{r}-\frac{M^{2}}{L_{s}}\right) \cdot s\right] i_{r q}+g \cdot \omega_{s}\left(L_{r}-\frac{M^{2}}{L_{s}}\right) i_{r d}+g \frac{V_{s} M}{L_{s}}$

We deduce from Eqs. (9) and (10), the rotor and stator currents expressions [21]:

$\mathrm{i}_{\mathrm{rd}}=\left[\mathrm{V}_{\mathrm{rd}}+\mathrm{g} \cdot \omega_{\mathrm{s}}\left(\mathrm{L}_{\mathrm{r}}-\frac{\mathrm{M}^{2}}{\mathrm{~L}_{\mathrm{s}}}\right) \mathrm{I}_{\mathrm{rq}}\right] /\left[\mathrm{R}_{\mathrm{r}}+\left(\mathrm{L}_{\mathrm{r}}-\frac{\mathrm{M}^{2}}{\mathrm{~L}_{\mathrm{s}}}\right) \cdot \mathrm{s}\right]$

$\mathrm{i}_{\mathrm{rq}}=\left[\mathrm{V}_{\mathrm{rq}}-\mathrm{g} \cdot \omega_{\mathrm{s}}\left(\mathrm{L}_{\mathrm{r}}-\frac{\mathrm{M}^{2}}{\mathrm{~L}_{\mathrm{s}}}\right) \mathrm{I}_{\mathrm{rd}}-\mathrm{g} \frac{\mathrm{V}_{\mathrm{s}} \mathrm{M}}{\mathrm{L}_{\mathrm{s}}}\right] /\left[\mathrm{R}_{\mathrm{r}}+\left(\mathrm{L}_{\mathrm{r}}-\frac{\mathrm{M}^{2}}{\mathrm{~L}_{\mathrm{s}}}\right) \cdot \mathrm{s}\right]$

$\mathrm{i}_{\mathrm{sd}}=-\frac{\mathrm{M}}{\mathrm{L}_{\mathrm{s}}} \mathrm{i}_{\mathrm{rd}}+\frac{\varphi_{\mathrm{s}}}{\mathrm{L}_{\mathrm{s}}}$

$\mathrm{i}_{\mathrm{sq}}=-\frac{\mathrm{M}}{\mathrm{L}_{\mathrm{s}}} \mathrm{i}_{\mathrm{rq}}$

The stator powers can be written as follows $[19,20]$ :

$\mathrm{p}_{\mathrm{s}}=-\mathrm{V}_{\mathrm{s}} \frac{\mathrm{M}}{\mathrm{L}_{\mathrm{s}}} \mathrm{i}_{\mathrm{rq}}$

$\mathrm{Q}_{\mathrm{s}}=\frac{\mathrm{V}_{\mathrm{s}}^{2}}{\mathrm{~W}_{\mathrm{s}} \mathrm{L}_{\mathrm{s}}}-\mathrm{V}_{\mathrm{s}} \frac{\mathrm{M}}{\mathrm{L}_{\mathrm{s}}} \mathrm{i}_{\mathrm{rd}}$

The electromagnetic torque is expressed as follows [21]:

$\mathrm{T}_{\mathrm{em}}=-\mathrm{p} \frac{\mathrm{M}}{\mathrm{L}_{\mathrm{s}}} \mathrm{i}_{\mathrm{rq}} \varphi_{\mathrm{s}}$

\section{Maximum power point (MPP) strategy}

To design the MPP control with mechanical speed regulation, the rotational velocity of the generator is kept at its reference. Consequently, the electromagnetic torque developed by DFIG is equal to its reference value imposed by the following control [17]:

$\mathrm{T}_{\mathrm{em}}=\mathrm{T}_{\mathrm{em}-\mathrm{opt}}$

Figure 2 shows the optimal electromagnetic torque $\mathrm{T}_{\text {em-opt }}$ for obtaining a rotational speed, which is equal to the optimal one as the following equation:

$\mathrm{T}_{\mathrm{em}-\mathrm{opt}}=\left[\mathrm{K}_{\mathrm{pmppt}}+\mathrm{K}_{\mathrm{imppt}} \cdot \frac{1}{\mathrm{~S}}\right] \cdot\left[\Omega_{\mathrm{mec}-\mathrm{opt}}-\Omega_{\mathrm{mec}}\right]$

The gains of the PI controller are calculated by the pole compensation technique and its expressions are presented as:

$\mathrm{K}_{\mathrm{imppt}}=\frac{1}{\tau \cdot \mathrm{f}}$ and $\mathrm{K}_{\mathrm{pmppt}}=\frac{-\mathrm{K}_{\mathrm{imppt}} \cdot \mathrm{J}_{\text {tot }}}{\mathrm{f}}$ with $\tau$ is the system time constant 


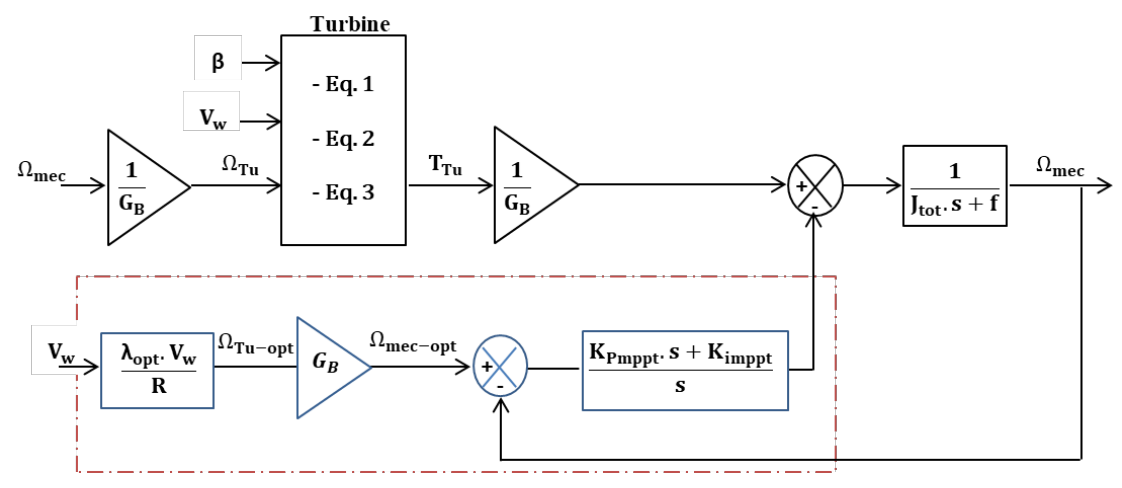

Figure 2 MPPT with speed control.

Application of the integral backstepping for controlling the DC link voltage and the GSC converter

DC control signal

Let us determine the derivative error $\varepsilon_{\mathrm{dc}}$ between the DC-link voltage and its desired [18]:

$\dot{\varepsilon}_{\mathrm{dc}}=\dot{\mathrm{V}}_{\mathrm{dc}}^{*}-\dot{\mathrm{V}}_{\mathrm{dc}}$, with $\dot{\mathrm{V}}_{\mathrm{dc}}=\frac{\dot{i}_{\mathrm{c}}}{\mathrm{C}}$

Selecting the first Lyapunov function associated with the DC bus voltage error with the error integral action value [22,23]:

$\mathrm{L}_{\mathrm{f}-\mathrm{dc}}=\frac{\varepsilon_{\mathrm{dc}}^{2}}{2}+\frac{\alpha_{\mathrm{dc}}^{2}}{2}$

Where $\alpha_{\mathrm{dc}}=\mathrm{C}_{\mathrm{dc}}^{\prime} \int_{0}^{t} \varepsilon_{d c} \cdot d(\tau), \mathrm{C}_{\mathrm{dc}}^{\prime}$ is the invariant of the integral action.

The derivative of Eq. (22) applies:

$\dot{\mathrm{L}}_{\mathrm{f}-\mathrm{dc}}=\varepsilon_{\mathrm{dc}} \cdot \dot{\varepsilon}_{\mathrm{dc}}+\alpha_{\mathrm{dc}} \cdot \mathrm{C}_{\mathrm{dc}}^{\prime} \cdot \varepsilon_{\mathrm{dc}}=\varepsilon_{\mathrm{dc}}\left(\dot{\mathrm{V}}_{\mathrm{dc}}^{*}-\frac{i_{c}}{c}+\alpha_{\mathrm{dc}} \cdot \mathrm{C}_{\mathrm{dc}}^{\prime}\right)$

This can be rewritten satisfying $\dot{\mathrm{L}}_{\mathrm{f}-\mathrm{dc}}<0$ as follows:

$\dot{\mathrm{L}}_{\mathrm{f}-\mathrm{dc}}=-\mathrm{C}_{\mathrm{dc}} \cdot \varepsilon_{\mathrm{dc}}^{2}$

Where $\mathrm{C}_{\mathrm{dc}}$ is a positive parameter. From Eqs. (22) and (24), we can write:

$\dot{\mathrm{V}}_{\mathrm{dc}}^{*}-\frac{i_{c}}{c}+\alpha_{\mathrm{dc}} \cdot \mathrm{C}_{\mathrm{dc}}^{\prime}=-\mathrm{C}_{\mathrm{dc}} \cdot \varepsilon_{\mathrm{dc}}$

$\mathrm{i}_{\mathrm{c}}^{*}=\mathrm{C} \cdot\left(\dot{\mathrm{V}}_{\mathrm{dc}}^{*}+\mathrm{C}_{\mathrm{dc}} \cdot \varepsilon_{\mathrm{dc}}+\alpha_{\mathrm{dc}} \cdot \mathrm{C}_{\mathrm{dc}}^{\prime}\right)$

On the other hand, we have:

$$
\begin{aligned}
& \mathrm{i}_{\mathrm{c}}^{*}=\frac{\mathrm{P}_{\mathrm{dc}}^{*}}{\mathrm{~V}_{\mathrm{dc}}} \\
& \mathrm{P}_{\mathrm{dc}}^{*}=\mathrm{P}_{\mathrm{gsc}}^{*}-\mathrm{P}_{\mathrm{rsc}} \\
& \mathrm{i}_{\mathrm{gq}}^{*}=\frac{\mathrm{P}_{\mathrm{gsc}}^{*}}{\mathrm{~V}_{\mathrm{g}}}
\end{aligned}
$$


Therefore, the quadrature grid current reference can be expressed as a function of the DC-link voltage as:

$$
\mathrm{i}_{\mathrm{gq}}^{*}=\frac{\mathrm{C} \cdot \mathrm{V}_{\mathrm{dc}} \cdot\left(\dot{\mathrm{V}}_{\mathrm{dc}}^{*}+\mathrm{C}_{\mathrm{dc}} \cdot \varepsilon_{\mathrm{dc}}+\alpha_{\mathrm{dc}} \cdot \mathrm{C}_{\mathrm{dc}}^{\prime}\right)+\mathrm{P}_{\mathrm{rsc}}}{\mathrm{V}_{\mathrm{g}}}
$$

\section{GSC control signals}

The expressions of the time derivative of grid currents are given in d-q frame reference as [23]:

$$
\begin{aligned}
& \frac{d i_{g q}}{d t}=\frac{1}{L_{f}}\left(-V_{g q}-R_{f} i_{g q}-\omega_{s} \cdot L_{f} \cdot i_{g d}+V_{g}\right) \\
& \frac{d i_{g d}}{d t}=\frac{1}{L_{f}}\left(-V_{g d}-R_{f} i_{g d}+\omega_{s} \cdot L_{f} \cdot i_{g q}\right)
\end{aligned}
$$
defined by:

The derivative of the errors of the component currents flowing through the filter $\varepsilon_{\mathrm{gsc} 1}$ and $\varepsilon_{\mathrm{gsc} 2}$ is

$\frac{\mathrm{d} \varepsilon_{\mathrm{gsc}}}{\mathrm{dt}}=\frac{\mathrm{di} \mathrm{i}_{\mathrm{gq}}^{*}}{\mathrm{dt}}-\frac{\mathrm{di} \mathrm{gq}}{\mathrm{dt}}$

$\frac{\mathrm{d} \varepsilon_{\mathrm{gsc2}}}{\mathrm{dt}}=\frac{\mathrm{di} \mathrm{id}_{\mathrm{gd}}^{*}}{\mathrm{dt}}-\frac{\mathrm{di} \mathrm{gd}}{\mathrm{dt}}$

By replacing the Eq. (31) and (32) in Eq. (33) and (34), respectively, the errors derivative becomes:

$$
\begin{aligned}
& \frac{d \varepsilon_{g s c 1}}{d t}=\frac{d i_{g q}^{*}}{d t}-\frac{1}{L_{f}}\left(-V_{g q}-R_{f} i_{g q}-\omega_{s} \cdot L_{f} \cdot i_{g d}+V_{g}\right) \\
& \frac{d \varepsilon_{g s c 2}}{d t}=\frac{d i_{g d}^{*}}{d t}-\frac{1}{L_{f}}\left(-V_{g d}-R_{f} i_{g d}+\omega_{s} \cdot L_{f} \cdot i_{g q}\right)
\end{aligned}
$$

Lyapunov function is given as value [23]:

$$
\mathrm{L}_{\mathrm{f}-\mathrm{g} 1}=\frac{\varepsilon_{\mathrm{gsc} 1}^{2}}{2}+\frac{\alpha_{\mathrm{g} 1}^{2}}{2} \text { And } \mathrm{L}_{\mathrm{f}-\mathrm{g} 2}=\frac{\varepsilon_{\mathrm{gsc} 2}^{2}}{2}+\frac{\alpha_{\mathrm{g} 2}^{2}}{2}
$$

Where $\alpha_{\mathrm{g} 1}=\mathrm{C}_{\mathrm{g} 1}^{\prime} \int_{0}^{t} \varepsilon_{g s c 1} \cdot d(\tau)$ and $\alpha_{\mathrm{g} 2}=\mathrm{C}_{\mathrm{g} 2}^{\prime} \cdot \int_{0}^{t} \varepsilon_{g s c 2} \cdot d(\tau), \mathrm{C}_{\mathrm{g} 1}^{\prime}$ and $\mathrm{C}_{\mathrm{g} 2}^{\prime}$ are the integral action invariants. The derivation of Lyapunov function is expressed as:

$$
\begin{aligned}
& \dot{\mathrm{L}}_{\mathrm{f}-\mathrm{g} 1}=\varepsilon_{\mathrm{gsc} 1} \cdot \dot{\varepsilon}_{\mathrm{gsc} 1}+\alpha_{\mathrm{g} 1} \cdot \mathrm{C}_{\mathrm{g} 1}^{\prime} \cdot \varepsilon_{\mathrm{gsc} 1}=\varepsilon_{\mathrm{gsc} 1}\left(\dot{\varepsilon}_{\mathrm{gsc} 1}+\alpha_{\mathrm{g} 1} \cdot \mathrm{C}_{\mathrm{g} 1}^{\prime}\right) \\
& \dot{\mathrm{L}}_{\mathrm{f}-\mathrm{g} 2}=\varepsilon_{\mathrm{gsc} 2} \cdot \dot{\varepsilon}_{\mathrm{gsc} 2}+\alpha_{\mathrm{g} 2} \cdot \mathrm{C}_{\mathrm{g} 2}^{\prime} \cdot \varepsilon_{\mathrm{gsc} 2}=\varepsilon_{\mathrm{gsc} 2}\left(\dot{\varepsilon}_{\mathrm{gsc} 2}+\alpha_{\mathrm{g} 2} \cdot \mathrm{C}_{\mathrm{g} 2}^{\prime}\right)
\end{aligned}
$$

In order to guarantee the stability of the system according to Lyapunov, the derivation of $\mathrm{L}_{\mathrm{f} \text {-gsc }}$ must be negative:

$\dot{\mathrm{L}}_{\mathrm{f}-\mathrm{gsc}}=-\mathrm{C}_{\mathrm{gsc} 1} \cdot \varepsilon_{\mathrm{gsc} 1}^{2}-\mathrm{C}_{\mathrm{gsc} 2} \cdot \varepsilon_{\mathrm{gsc} 2}^{2}$

The virtual command of rotor current is deduced as:

$$
\begin{aligned}
& \frac{d i_{g q}^{*}}{d t}-\frac{1}{L_{f}}\left(-V_{g q}-R_{f} i_{g q}-\omega_{s} \cdot L_{f} \cdot i_{g d}+V_{g}\right)+\alpha_{g 1} \cdot C_{g 1}^{\prime}=-C_{g s c 1} \cdot \varepsilon_{g s c 1} \\
& \frac{d i_{g d}^{*}}{d t}-\frac{1}{L_{f}}\left(-V_{g d}-R_{f} i_{g d}-\omega_{s} \cdot L_{f} \cdot i_{g q}\right)+\alpha_{g 2} \cdot C_{g 1}^{\prime}=-C_{g s c 2} \cdot \varepsilon_{g s c 2}
\end{aligned}
$$

Which gives the expression of the actual global command $V_{\mathrm{gd}}$ and $\mathrm{V}_{\mathrm{gq}}$ are defined by:

$\mathrm{V}_{\mathrm{gq}}=-\mathrm{L}_{\mathrm{f}} \cdot\left[\frac{\mathrm{d}_{\mathrm{gq}}^{*}}{\mathrm{dt}}+\alpha_{\mathrm{g} 1} \cdot \mathrm{C}_{\mathrm{g} 1}^{\prime}+\mathrm{C}_{\mathrm{gsc} 1} \cdot \varepsilon_{\mathrm{gsc} 1}\right]-\mathrm{R}_{\mathrm{f}} \mathrm{i}_{\mathrm{gq}}-\omega_{\mathrm{s}} \cdot \mathrm{L}_{\mathrm{f}} \cdot \mathrm{i}_{\mathrm{gd}}+\mathrm{V}_{\mathrm{g}}$ 
$\mathrm{V}_{\mathrm{gd}}=-\mathrm{L}_{\mathrm{f}} \cdot\left[\frac{\mathrm{di}_{\mathrm{gd}}^{*}}{\mathrm{dt}}+\alpha_{\mathrm{g} 2} \cdot \mathrm{C}_{\mathrm{g} 2}^{\prime}+\mathrm{C}_{\mathrm{gsc} 2} \cdot \varepsilon_{\mathrm{g} 2}\right]-\mathrm{R}_{\mathrm{f}} \mathrm{i}_{\mathrm{gd}}+\omega_{s} \cdot \mathrm{L}_{\mathrm{f}} \cdot \mathrm{i}_{\mathrm{gq}}$

\section{Application of the adaptive PSO for controlling the RSC}

\section{PSO mathematical mode}

The mathematical description of the PSO algorithm is made as follows [24]:

$V_{i j}(t+1)=W \cdot V_{i j}(t)+C_{1} \cdot r_{1} \cdot\left(P_{\text {best }_{i j}}-X_{i j}(t)\right)+C_{2} \cdot r_{2} \cdot\left(G_{\text {best }_{j}}-X_{i j}(t)\right)$

The location of particles is depending on the previous location and velocity as the following expression:

$X_{i j}(t+1)=V_{i j}(t+1)+X_{i j}(t)$

Where $\mathrm{P}_{\text {best }}$ is the best previous location (giving the minimum fitness value) of any particle is recorded, and $G_{\text {best }}$ is the best value attained so far by any particle in the neighborhood of that particle. The factors $r_{1}$ and $r_{2}$ are the random numbers between [0-1]. However, $C_{1}$ and $C_{2}$ are the acceleration constants denoted the cognitive and social parameters, which are determined, respectively [25]:

$\mathrm{C}_{1}=\mathrm{C}_{1 \max }-\frac{\mathrm{C}_{1 \max }-\mathrm{C}_{1 \min }}{\mathrm{N}_{\mathrm{iter}}} * \mathrm{k}$

$\mathrm{C}_{2}=\mathrm{C}_{2 \max }+\frac{\mathrm{C}_{2 \max }-\mathrm{C}_{2 \min }}{\mathrm{N}_{\mathrm{iter}}} * \mathrm{k}$

Where $\mathrm{W}$ is the inertia weight factor that is used as control parameter for the swarm velocity. In this work, the $\mathrm{W}$ is expressed by the following equation [26]:

$\mathrm{W}=\mathrm{W}_{\text {max }}-\frac{\mathrm{W}_{\max }-\mathrm{W}_{\min }}{\mathrm{N}_{\text {iter }}} * \mathrm{k}$

Where $\mathrm{N}_{\text {iter }}$ is the upper limit number of iterations and $\mathrm{k}$ is the current number of iterations. $\mathrm{W}_{\max }$ and $\mathrm{W}_{\min }$ are the maximum and the minimum weights, respectively. The particle swarm is also characterized by " $d$ " the dimension of the problem and " $n$ " the size of the swarm $[25,26]$.

\section{Problem identification}

The indirect vector control with open loop regulates powers in an open loop. However, the rotor currents $\left(\mathrm{i}_{\mathrm{rq}}, \mathrm{i}_{\mathrm{rd}}\right)$ are regulated by a closed-loop. The current $\mathrm{i}_{\mathrm{rq}}^{*}$ is obtained from input power reference to control active power. The reactive power is controlled by regulating $\mathrm{i}_{\mathrm{rd}}^{*}$, which is computed from the $\mathrm{Q}_{\mathrm{s}}{ }^{*}$. These current references can be written as follows [20]:

$\mathrm{i}_{\mathrm{rq}}^{*}=-\frac{\mathrm{L}_{\mathrm{s}}}{\mathrm{M} \cdot \mathrm{v}_{\mathrm{s}}} \cdot \mathrm{P}_{\mathrm{s}}^{*}$

$\mathrm{i}_{\mathrm{rd}}^{*}=-\frac{\mathrm{L}_{\mathrm{s}}}{\mathrm{M} \cdot \mathrm{V}_{\mathrm{s}}} \cdot\left(\mathrm{Q}_{\mathrm{s}}^{*}-\frac{\mathrm{V}_{\mathrm{s}}^{2}}{\omega_{\mathrm{s}} \cdot \mathrm{L}_{\mathrm{s}}}\right)$

The voltage references are expressed as follows [20]:

$\mathrm{V}_{\mathrm{rq}}^{*}=\left[\mathrm{i}_{\mathrm{rq}}^{*}-\mathrm{i}_{\mathrm{rq}}\right] \cdot\left[\mathrm{K}_{\mathrm{p}-\mathrm{rsc} 1}+\mathrm{K}_{\mathrm{i}-\mathrm{rsc} 1} \cdot \frac{1}{\mathrm{~s}}\right]+\mathrm{e}_{\mathrm{rd}}+\mathrm{Vs}^{\prime}$

$\mathrm{V}_{\mathrm{rd}}^{*}=\left[\mathrm{i}_{\mathrm{rd}}^{*}-\mathrm{i}_{\mathrm{rd}}\right] \cdot\left[\mathrm{K}_{\mathrm{p}-\mathrm{rsc} 2}+\mathrm{K}_{\mathrm{i}-\mathrm{rsc} 2} \cdot \frac{1}{\mathrm{~s}}\right]+\mathrm{e}_{\mathrm{rq}}$

Where $e_{r d}=g \cdot \omega_{s} \cdot\left(L_{r}-\frac{M^{2}}{L_{s}}\right) \cdot i_{r d} ; \quad e_{r q}=g \cdot \omega_{s} \cdot\left(L_{r}-\frac{M^{2}}{L_{s}}\right) \cdot i_{r q} ; \quad V s^{\prime}=g \cdot \frac{V_{s} M}{L_{s}}$

The PI gains can be calculated utilizing the pole compensation methodology using $\mathrm{T}_{\mathrm{rsc}}$ as the system time constant for the RSC controller: 
$\mathrm{K}_{\mathrm{p}-\mathrm{rsc} 1,2}=\frac{1}{\mathrm{~T}_{\mathrm{rsc}}} \cdot\left(\mathrm{L}_{\mathrm{r}}-\frac{\mathrm{M}^{2}}{\mathrm{~L}_{\mathrm{s}}}\right)$ and $\mathrm{K}_{\mathrm{i}-\mathrm{rsc} 1,2}=\frac{\mathrm{K}_{\mathrm{prsc}} \cdot \mathrm{R}_{\mathrm{r}}}{\left(\mathrm{L}_{\mathrm{r}}-\frac{\mathrm{M}^{2}}{\mathrm{~L}_{\mathrm{s}}}\right)}$

so, as shown in Eq. (55), the gains of the regulators are entirely dependent on the generator settings. Any changes in parameter values have an impact on the stability of the system. As a result, the problem is formulated as reducing the effect of parameter variation on response time while also decreasing the error between rotor currents.

\section{Proposed intelligent control design}

The integral absolute error (IAE) is defined by the Eq. (56) as [27]:

$\operatorname{IAE}=\int_{0}^{\mathrm{T}} \operatorname{sim}|\mathrm{e}(\mathrm{t})| \mathrm{dt}$

Where $T_{\text {sim }}$ is the simulation time and e $(t)$ is the tracking error. The signal error is determined based on the differences between the reference input and the desired output. The errors are calculated as follows:

$\left\{\begin{array}{l}\mathrm{e}_{1}=\mathrm{e}_{\mathrm{RSC} 1}=\mathrm{i}_{\mathrm{rq}}^{*}-\mathrm{i}_{\mathrm{rq}} \\ \mathrm{e}_{2}=\mathrm{e}_{\mathrm{RSC} 2}=\mathrm{i}_{\mathrm{rd}}^{*}-\mathrm{i}_{\mathrm{rd}}\end{array}\right.$

The objective function is determined by the weighted sum of errors given in Eq. (58). The integral absolute error (IAE) performance criterion is associated with the objective function presented in Eq. (59). By minimizing the fitness function employing the PSO algorithm, the optimal parameters are obtained with fast convergence of the algorithm [28]:

$$
\begin{aligned}
& \mathrm{F}(\mathrm{t})=\sum_{\mathrm{i}=1}^{\mathrm{n}} \mathrm{W}_{\mathrm{i}} \cdot\left|\mathrm{e}_{\mathrm{i}}(\mathrm{t})\right| \\
& \operatorname{Obj}(\mathrm{t})=\int_{0}^{\mathrm{T}}{ }^{\operatorname{sim}} \mathrm{F}(\mathrm{t}) d \mathrm{t}
\end{aligned}
$$

Where $\mathrm{n}$ is the maximum number of the computed errors and $\mathrm{W}_{\mathrm{i}}$ are the nonnegative weight factors related to the fitness function, which their sum realizes the Eq. (60) below [29]:

$\sum_{\mathrm{i}=1}^{\mathrm{n}} \mathrm{W}_{\mathrm{i}}=1$ with $\mathrm{i}=1,2$

In this paper, the adaptive weighted PSO is applied to evaluate fitness. Equal weights are considered. The optimization of each particle is performed on $\mathrm{Obj}(\mathrm{t})$, similar to the single-objective case.

\section{Optimization procedure} follows:

As mentioned in $[18,30]$, the steps of the searching procedure for the PSO technique are listed as

Step 1: Randomly generate an initial population.

Step 2: If a prescribed number of iterations are reached, then the algorithm is stopped.

Step 3: Appraise the target function of every particle as defined in Eq. (58) and record the best previous position (Pi) of each particle and the global best position $(\mathrm{Pg})$.

Step 4: Perform the improved velocity updating of formula (45) and the position updating of formula (46) for each particle.

Verify the velocity constraint conditions by using the following expressions [29]:

$V_{i}(t+1)=\left\{\begin{array}{ccc}V_{\text {max }} & \text { if } & V_{i}(t+1)>V_{\text {max }} \\ V_{i}(t+1) & \text { if } & V_{\text {min }}<V_{i}(t+1)<V_{\text {max }} \\ V_{\text {min }} & \text { if } & V_{i}(t+1)<V_{\text {min }}\end{array}\right.$

Verify the position constraint conditions of particles as follows:

$x_{i}(t+1)=\left\{\begin{array}{ccc}x_{\max } & \text { if } & x_{i}(t+1)>x_{\max } \\ x_{i}(t+1) & \text { if } & x_{\text {min }}<V_{i}(t+1)<x_{\text {max }} \\ x_{\text {min }} & \text { if } & x_{i}(t+1)<x_{\text {min }}\end{array}\right.$ 
Step 5: Exit if a termination criterion is met Else go back to step 2.

End

Figure 3 illustrates the pseudo-code of basic PSO [31]:

Random generate an initial population

Repeat

for $i=1$ to population size do

Calculate fitness value $f\left(x_{i j}\right)$;

if $f\left(x_{i j}(t)\right)>f(p i(t))$ then $p i(t)=x_{i j}(t)$

$f\left(p_{g}(t)\right)=\min (f(p i(t)))$

end

for $d=1$ to dimension do

Velocity updating (Eq. (45))

end

Position updating (Eq. (46))

end

Until "Maximum iteration is met"

Figure 3 Pseudo code of PSO. 
Figure 4 depicts the flowchart that can be used to coordinate the above-mentioned steps.

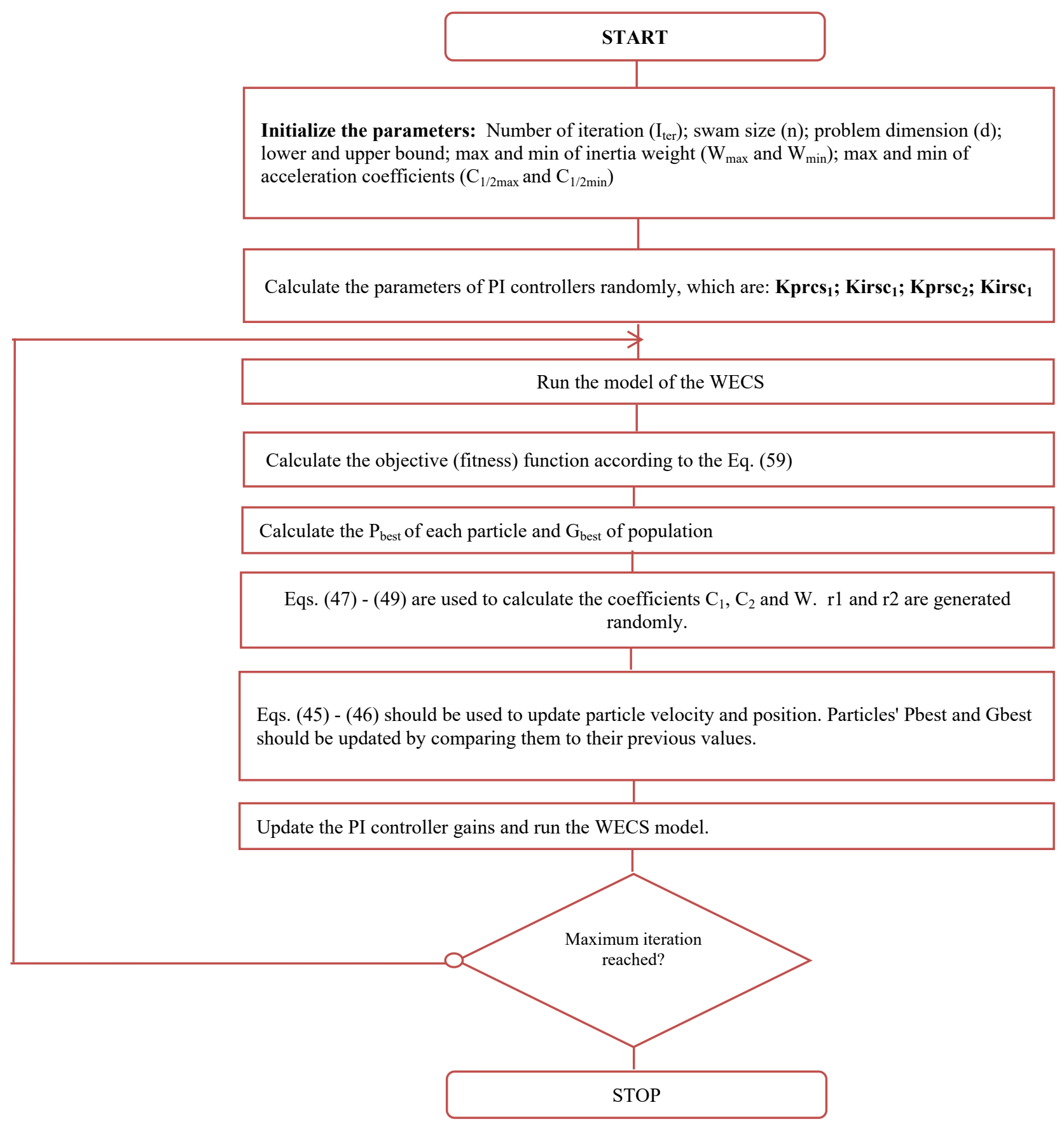

Figure 4 Flowchart of PSO algorithm.

\section{Results and discussion}

The whole system (WECS), as illustrated in Figure 1, is modeled using the before-cited equations and performed employing matlab/simulink. To guaranty a unity power factor, both the reactive power references $\mathrm{Qg}^{*}$ and $\mathrm{Qs}^{*}$ are set to $0 \mathrm{VAR}$. These are the adaptive PSO pilots and the RSC of the generator. However, the integral backstepping (IBC) commands are the grid side converter. The MPP strategy based 
on the PI regulator is established. The results are obtained and compared between the proposed methods and the indirect vector control based on the PI regulator.

Table 1 shows the parameters of the DFIG, which is employed in the simulation.

Table 1 Set of parameters used in the simulation.

\begin{tabular}{llll}
\hline Turbine & Radius of blade & $\mathrm{R}$ & $51,583 \mathrm{~m}$ \\
& Coefficient of multiplier & $\mathrm{G}_{\mathrm{B}}$ & 47,23 \\
& Total moment of inertia & $\mathrm{J}_{\mathrm{tot}}$ & $1000 \mathrm{~kg} \cdot \mathrm{m}^{2}$ \\
\hline DFIG & DFIG rated power & $\mathrm{Ps}$ & $5 \mathrm{MW}$ \\
& Stator leakage inductance & $\mathrm{Ls}$ & $1,2721 \mathrm{mH}$ \\
& Rotor resistance & $\mathrm{Rr}$ & $1,446 \mathrm{~m} \Omega$ \\
& Rotor leakage inductance & $\mathrm{Lr}$ & $1,1194 \mathrm{mH}$ \\
& Mutual inductance & $\mathrm{M}$ & $0,55187 \mathrm{mH}$ \\
& Stator line to line voltage & $\mathrm{Vs}$ & $950 \mathrm{~V}$ \\
\hline Capacity & DC-link capacitance & $\mathrm{C}$ & $4400 \mu \mathrm{F}$ \\
\hline Filter RL & Resistor of the filter & $\mathrm{R}_{\mathrm{f}}$ & $20 \Omega$ \\
& Inductance of the filter & $\mathrm{L}_{\mathrm{f}}$ & $0,08 \mathrm{H}$ \\
\hline
\end{tabular}

Table 2 gives the parameters used for establishing the code of the adaptive PSO.

Table 2 APSO code parameters.

\begin{tabular}{cc}
\hline Parameters & Value \\
\hline Population size & 20 \\
Number of parameters & 4 \\
Number of iterations & 20 \\
$\mathrm{~W}_{\max }$ & 0.9 \\
$\mathrm{~W}_{\min }$ & 0.4 \\
$\mathrm{C}_{1 \max }=\mathrm{C}_{2 \max }$ & 2 \\
$\mathrm{C}_{1 \min }=\mathrm{C}_{2 \min }$ & 0.1 \\
\hline
\end{tabular}

Figure 5 presents the variable wind speed profile that has been applied to drive the wind energy system. As you can see, the wind speed begins at $9 \mathrm{~m} \mathrm{~s}^{-1}$, at $0.2 \mathrm{~s}$ the wind speed suddenly varies at $11 \mathrm{~m}$ $\mathrm{s}^{-1}$, at $0.4 \mathrm{~s}$ the wind speed quickly evolves to $12.5 \mathrm{~m} \mathrm{~s}^{-1}$ and at $0.6 \mathrm{~s}$, it drops to $10 \mathrm{~m} \mathrm{~s}^{-1}$ to test the performance and the superiority of the advised methods.

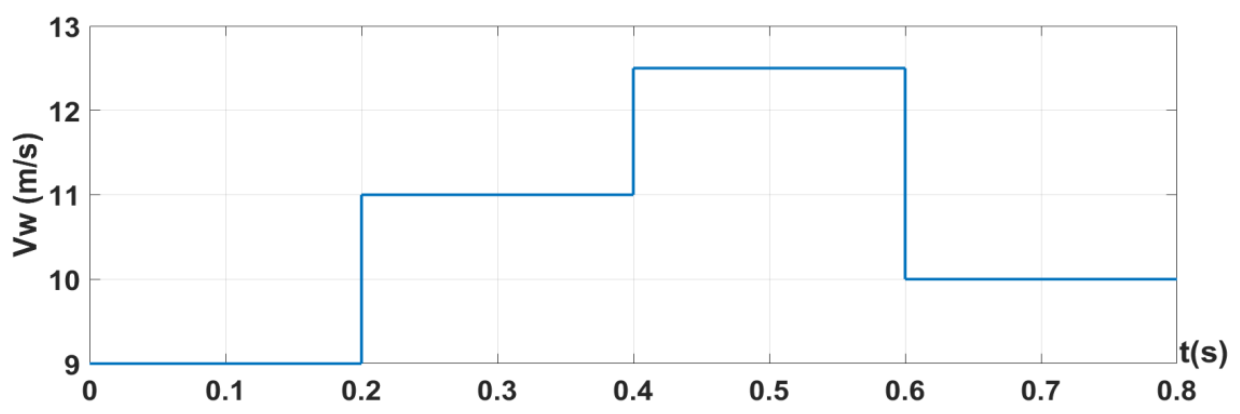

Figure 5 Wind speed profile $\left(\mathrm{m} \mathrm{s}^{-1}\right)$. 
Figure 6 shows the mechanical speed computed by the MPPT algorithm. As you can see, the time response is in the order of $1 \mathrm{~m} \mathrm{~s}$ and is considered very satisfactory compared to the quick variation of the wind velocity. Also, the rotational speed tracks and the input reference with a static error are equal to 0 . The rated generator speed that corresponds to the rated value of the wind speed is $104.7 \mathrm{rad} \mathrm{s}^{-1}$. The latter corresponds to 3 pairs of poles of the generator.

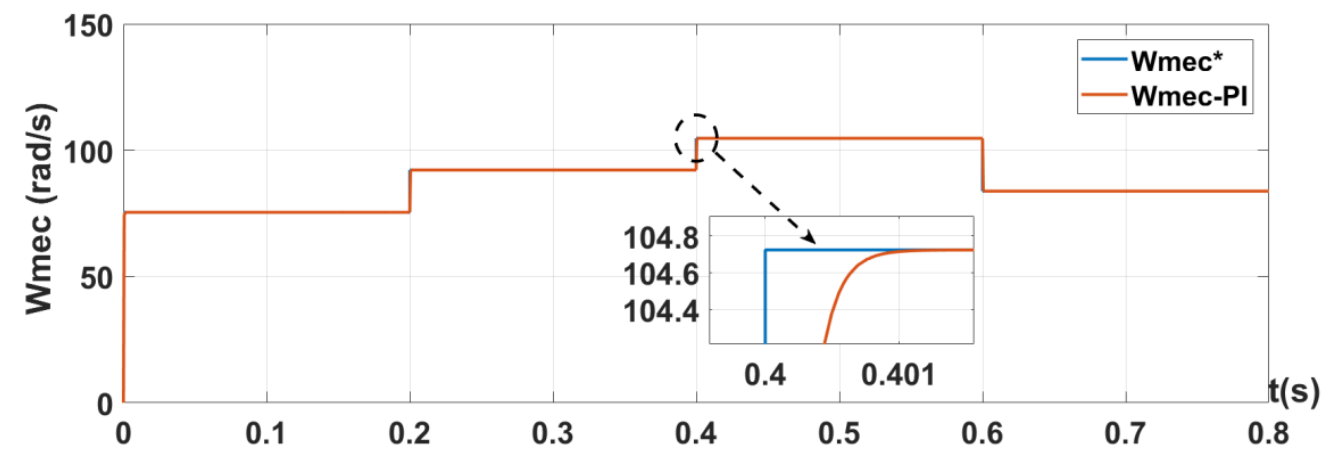

Figure 6 Mechanical rotation speed $\left(\mathrm{rad} \mathrm{s}^{-1}\right)$.

Figure 7 presents the d-q components of the gird voltage computed by the PLL based on the PI controller. Unlike the $\mathrm{d}$ component, which is fixed to 0 , the q component is regulated to the rated maximum line- neural voltage value.

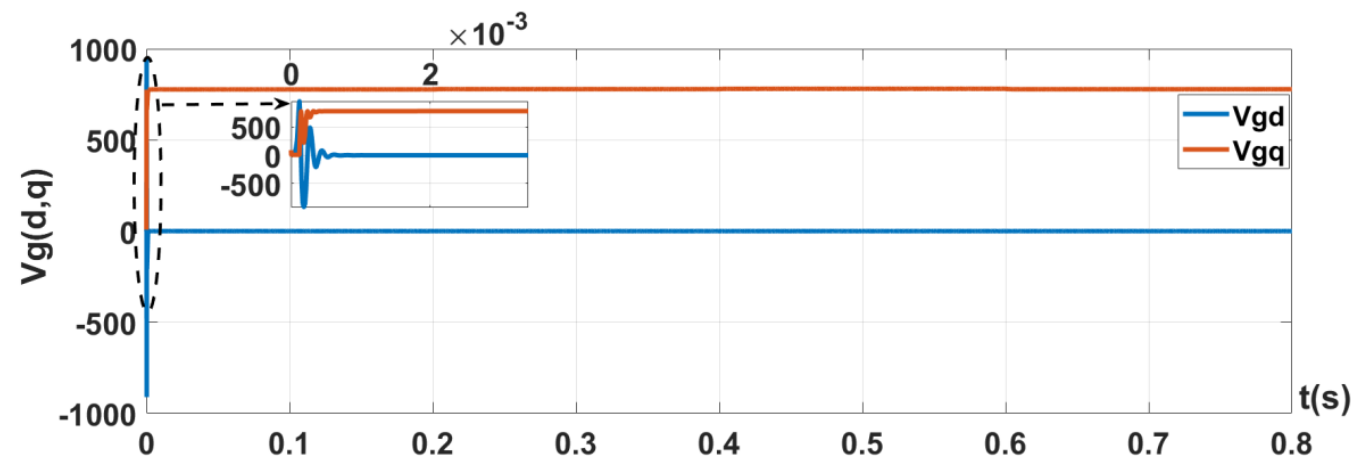

Figure 7 Grid voltage components computed by PLL.

Figure 8 illustrates that the stator active power follows its set point and shows a comparison between the adaptive PSO and indirect vector control. The time response is ameliorated from 8.8 to $4.3 \mathrm{~m}$ s. The static error is significantly reduced and is close to 0 .

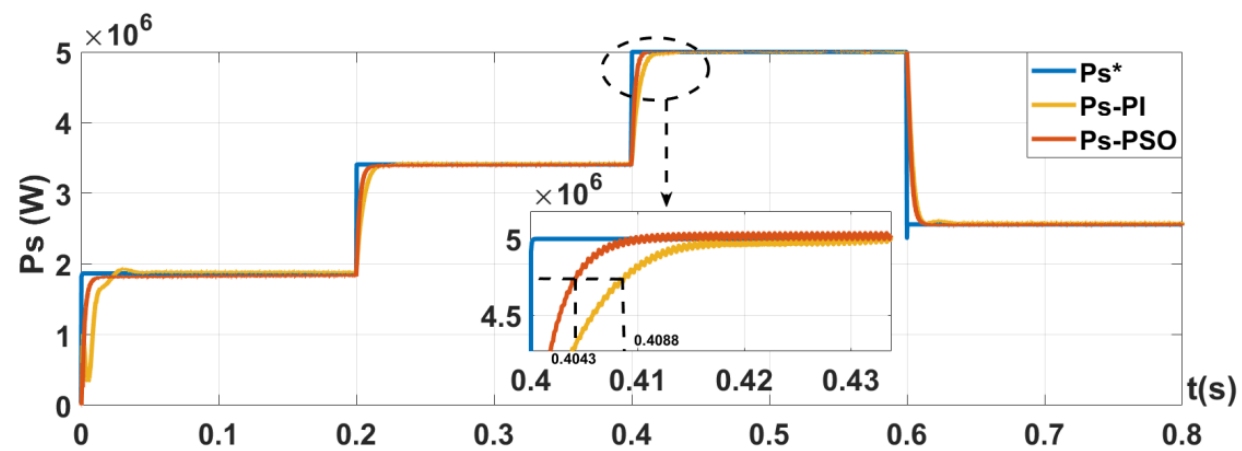

Figure 8 Stator active power (W). 
Figure 9 demonstrates the reactive power computed by the 2 techniques. It can be seen clearly that the recommended method reduces the power overshoot in the transitory regime, ameliorates the response, and minimizes the static error.

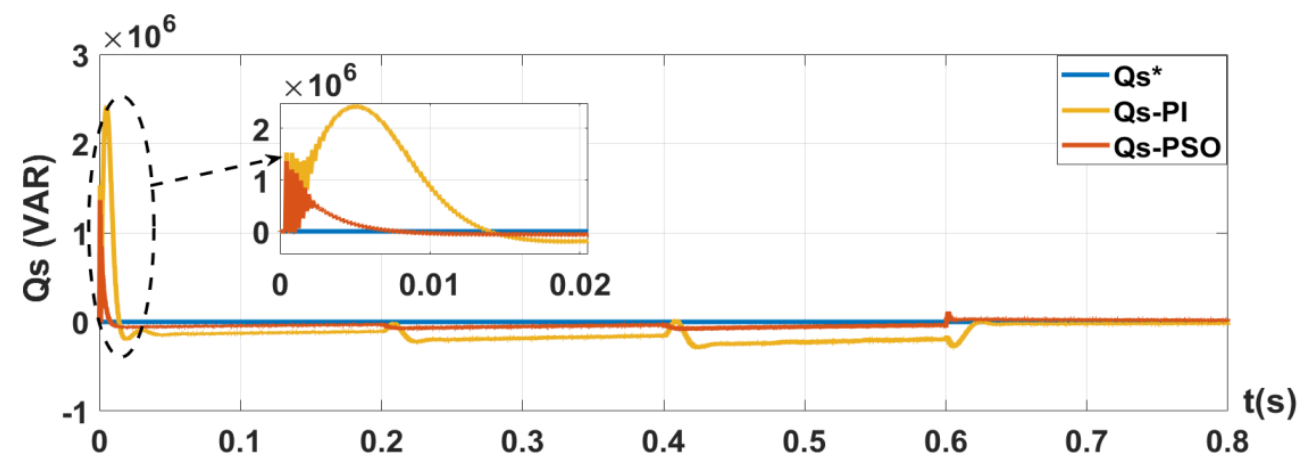

Figure 9 Stator reactive power (VAR).

Figure 10 demonstrates that the power factor is regulated to 1 by the 2 methods. As you can see, the PSO maintains the power factor to one better than the IFOC. At 0.4 and $0.5 \mathrm{~s}$, the proposed method ignores the wind profile variations.

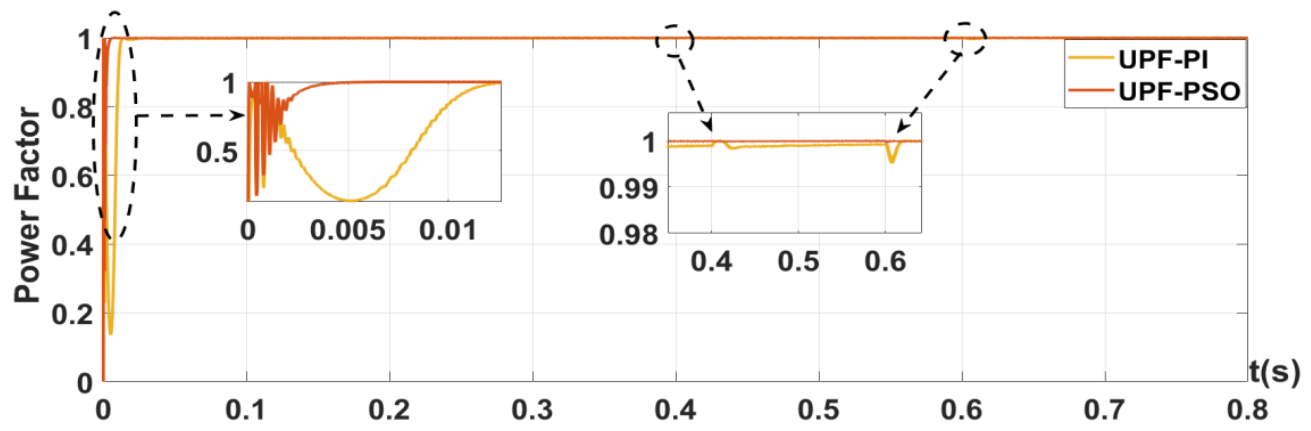

Figure 10 Unit power factor.

Figure 11 presents the DC-link voltage computed by the conventional PI, the conventional backstepping (BC), and the integral backstepping control (IBC). The positive constants of backstepping are $C_{d c}=3 e+4, C_{d c}^{\prime}=1 e+8, C_{g s c 1}=1 e 7, C_{g 1}^{\prime}=1 e+12, C_{g s c 2}=1 e+9$ and $C_{g 2}^{\prime}=1 e+12$. Remarkably, the overshoot of the DC link voltage is considerably reduced from 2400 to $20 \mathrm{~V}$. As you can see, in the zoom, at $0.4 \mathrm{~s}$, the response time is greatly improved by the integral backstepping when the wind velocity changes.

Also, the static error is equal to 0 . The integral backstepping ensures better robustness against the variable conditions of the wind speed.

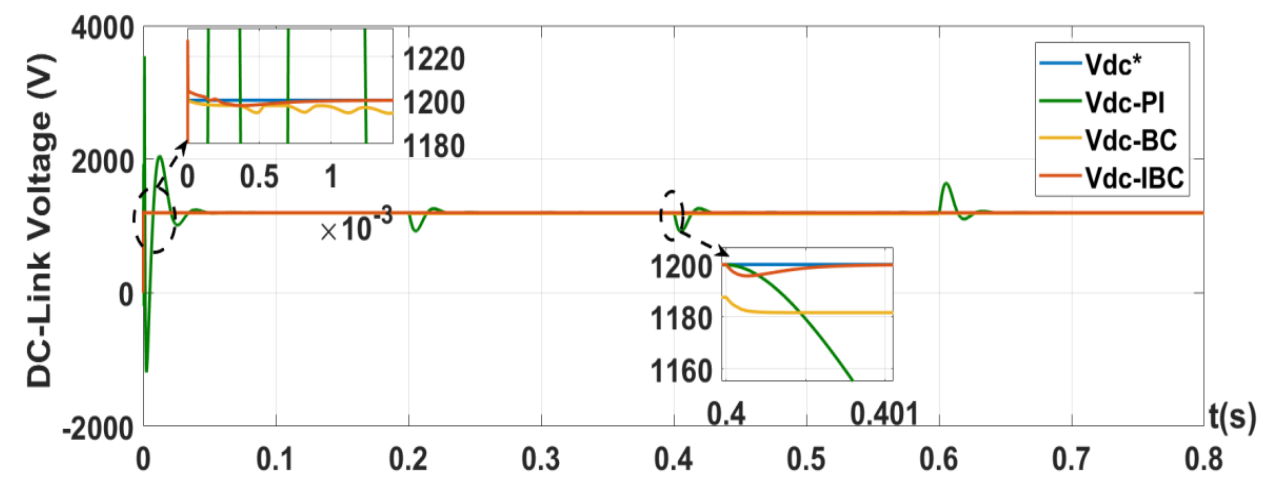

Figure 11 DC-link voltage $(\mathrm{V})$. 
Figure 12 illustrates the influence of the variation of the rotor resistance and inductance of the produced power. These parameters are changed by $+100 \%$ (Rated values $+100 \%$ ). As you can see in the zoom, the APSO presents better robustness against parameter change than the indirect vector control and reveals a better tracking reference with a fluctuation that can be ignored in a steady-state.

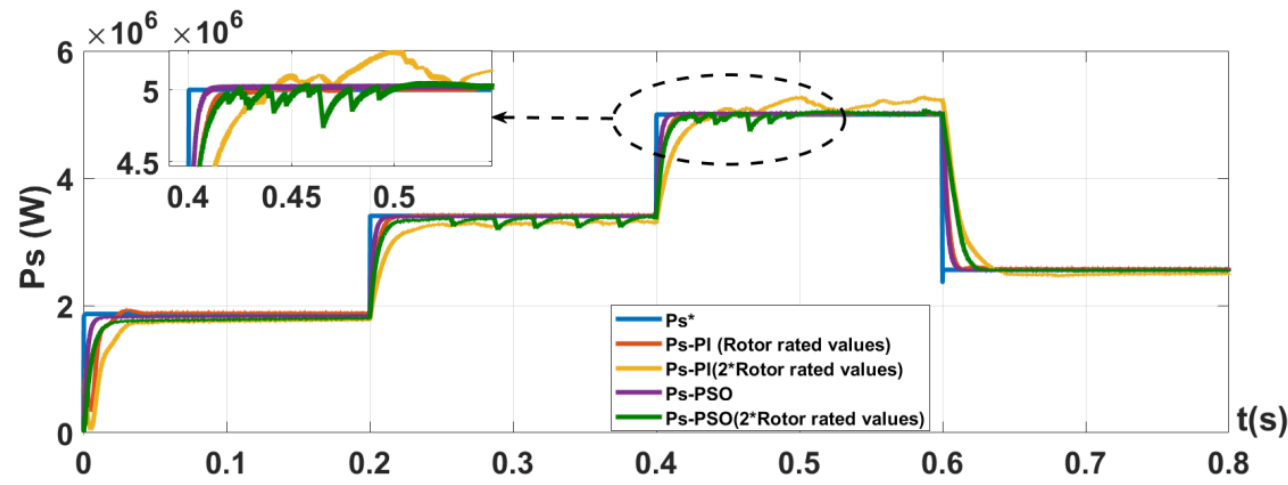

Figure 12 Stator active power (rotor parameters variation).

Figure 13 shows the influence of the variation of the rotor resistance and inductance of the reactive power. As you can see, the suggested method maintains better robustness against the variable parameters of the rotor than indirect vector control based on PI controller.

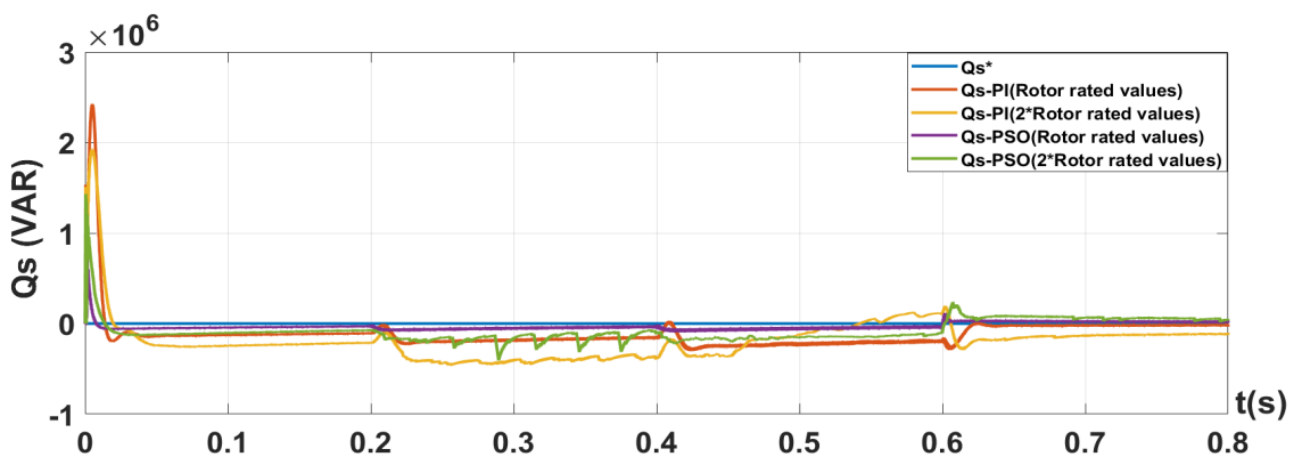

Figure 13 Reactive power (rotor parameters variation).

Figure 14 shows the influence of the variation of the stator inductance of the reactive power. This parameter is changed by $+100 \%$ (Rated value $+100 \%$ ). As you can see in the zoom, the APSO presents better robustness against stator inductance change than the indirect vector control and reveals a better tracking reference.

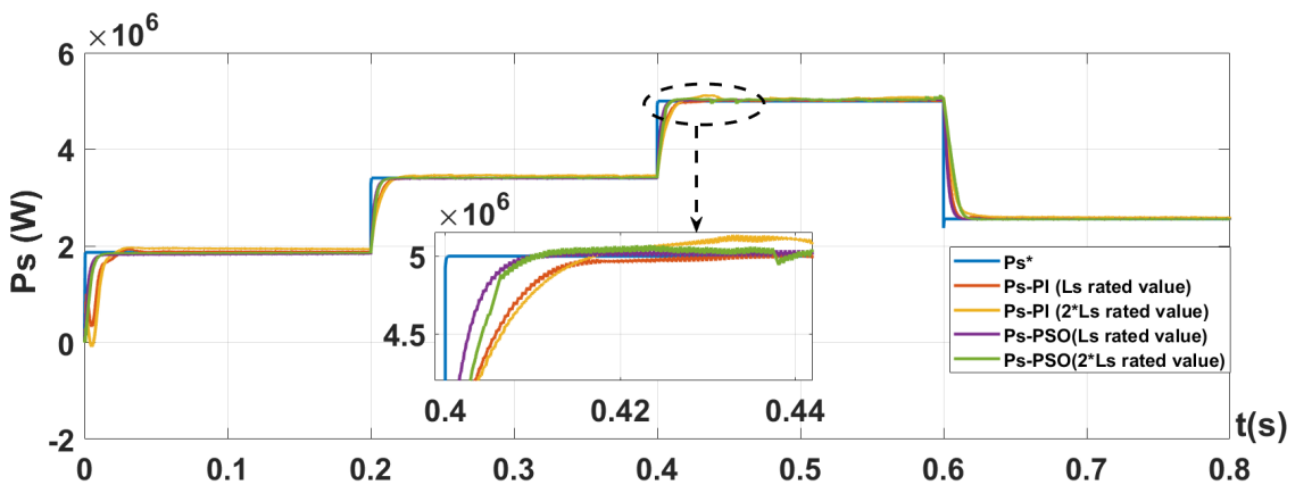

Figure 14 Active power (stator inductance variation). 
Figure 15 illustrates the influence of the variation of the stator inductance of the reactive power. It is notable that the proposed method shows better robustness against the variation of the stator inductance than indirect vector control based on the PI controller.

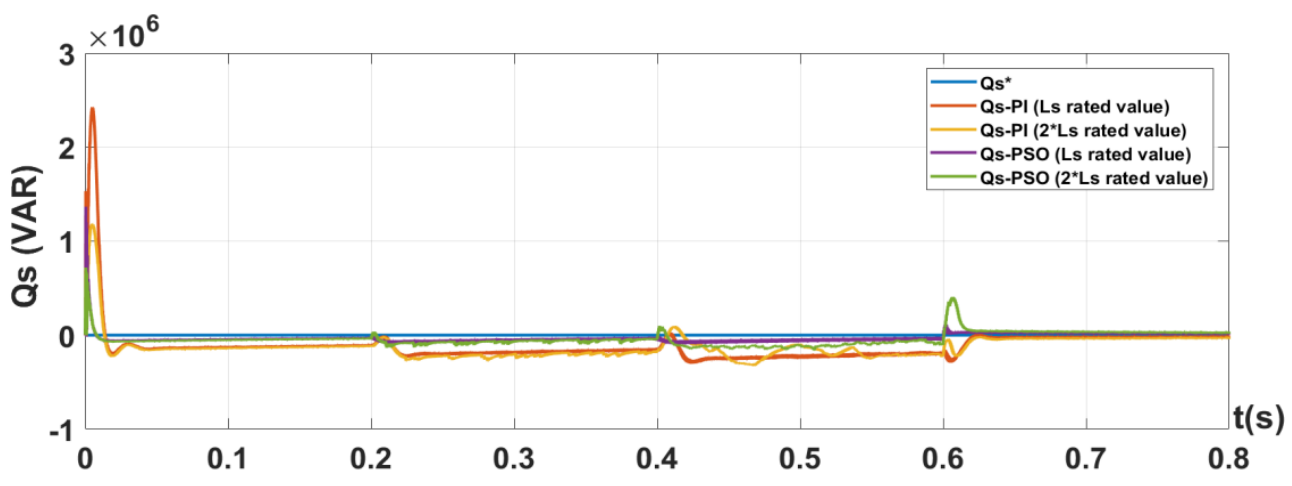

Figure 15 Reactive power (stator inductance variation).

\section{Conclusions}

In this paper, the combination of the integral backstepping controller and adaptive PSO is successfully realized for piloting the wind energy system conversion (WECS) based on a doubly-fed induction generator. The DFIG stator is directly branched to the grid, and the rotor is linked via back-toback converters.

First, the whole wind energy chain is modeled and simulated under variable wind speed conditions using the indirect field-oriented control based on conventional PI controllers. Besides, the MPP is designed by dint of the PI controller, with the gains are computed by the pole compensation method.

Second, the integral backstepping controller is proposed for controlling the DC link voltage and the grid side converter. This technique is compared with conventional backstepping and indirect vector control. The stability of the system is based on the Lyapunov function. The suggested method guarantees better stability provides a reduced overshoot of the DC link voltage by $99.16 \%$ and shows a faster response time against the quick wind speed variation than conventional backstepping and indirect vector control.

Then, the gains of the PI controllers for the RSC are tuned by employing adaptive weights PSO. The results of the optimal controller based on the APSO are compared with those found by the conventional PI controller. The robustness test is performed by varying the rotor and stator parameters of the generator. Simulation results indicate that the APSO technique brings a faster transient response, $4.3 \mathrm{~m} \mathrm{~s}$, with ameliorated tracking error and good robustness compared to the indirect vector control.

The proposed control can be used in various applications, including PV system control, PV-wind hybrid system, battery energy storage, active power filters, etc.

The future works will focus on: Regulating the WECS using DFIG by combining the PSO with other types of algorithms such as neural networks or fuzzy logic controllers, and many others and testing the robustness of the proposed method in the face of grid faults.

\section{References}

[1] KB Tawfiq, AS Mansour, HS Ramadan, M Becherif and EE El-Kholy. Wind energy conversion system topologies and converters: Comparative review. Energ. Proc. 2019; 162, 28-47.

[2] TK Roy, MA Mahmud and AMT Oo. Nonlinear backstepping controller design for improving fault ride through capabilities of DFIG-based wind farms. In: Proceedings of the 2018 IEEE Power \& Energy Society General Meeting, Portland OR, USA. 2018, p. 1-5.

[3] A Khaled, AY Abdelaziz, HM El-Helw and M Ezzat. Protecting doubly fed induction generator's converter using a filter based TCR. In: Proceedings of the 2020 IEEE International Conference on Environment and Electrical Engineering and 2020 IEEE Industrial and Commercial Power Systems Europe, Madrid, Spain. 2020, p. 1-4.

[4] Y Iherdane, CE Bekkali, ME Ghamrasni, S Mensou and B Bossoufi. Improved wind system using non-linear power control. Indonesian J. Electr. Eng. Comput. Sci. 2019; 14, 1148-58.

[5] M Elmahfoud, B Bossoufi and M taoussi. Comparative study between backstepping adaptive and field oriented controls for doubly fed induction motor. Eur. J. Electr. Eng. 2020; 22, 209-21. 
[6] ME Ghamrasni, H Mahmoudi, A Lagrioui and B Bossoufi. Comparison of power control methods of DFIG for wind turbines. In: Proceedings of the $6^{\text {th }}$ International Renewable and Sustainable Energy Conference, Rabat, Morocco. 2018, p. 1-8.

[7] Y Djeriri. Lyapunov-based robust power controllers for a doubly fed induction generator. Iranian J. Electr. Electron. Eng. 2020; 16, 551-8.

[8] M Benakcha, L Benalia, DE Tourqui and A Benakcha. Backstepping control of dual stator induction generator used in wind energy conversion system. Int. J. Renew. Energ. Res. 2018; 8, 384-95.

[9] TM Anteneh, AO Salau, TF Agajie and EA Hailu. Design and implementation of a direct torque controller for a three phase induction motor based on DSP. Int. J. Appl. Eng. Res. 2019; 14, 4181-7.

[10] D Cherifi and Y Miloud. Hybrid control using adaptive fuzzy sliding mode control of doubly fed induction generator for wind energy conversion system. Periodica Polytechnica Electr. Eng. Comput. Sci. 2020; 64, 374-81.

[11] B Rached, M Elharoussi and E Abdelmounim. Design and investigations of MPPT strategies for a wind energy conversion system based on doubly fed induction generator. Int. J. Electr. Comput. Eng. 2020; 10, 4770-81.

[12] H Rahmanifard and T Laksina. Application of artificial intelligence techniques in the petroleum industry: a review. Artif. Intell. Rev. 2019; 52, 2295-318.

[13] OB Belghith, L Sbita and F Bettaher. MPPT design using PSO technique for photovoltaic system control comparing to fuzzy logic and P\&O controllers. Energ. Power Eng. 2016; 8, 349-66.

[14] M Taleb, M Cherkaoui and M Hbib. Using particle swarm optimization to enhance PI controller performances for active and reactive power control in wind energy conversion systems. IOP Conf. Ser. Earth Environ. Sci. 2018; 154, 012015.

[15] R Laina, F Lamzouri, E Boufounas, AE Amrani and I Boumhidi. Intelligent control of a DFIG wind turbine using a PSO evolutionary algorithm. Proc. Comput. Sci. 2018; 127, 471-80.

[16] OP Bharti, RK Saket and SK Nagar. Controller design for doubly fed induction generator using particle swarm optimization technique. Renew. Energ. 2017; 114, 1394-406.

[17] Y Errami, A Obbadi and S Sahnoun. Control of PMSG wind electrical system in network context and during the MPP tracking process. Int. J. Syst. Contr. Comm. 2020; 11, 200-25.

[18] S Kahla, Y Soufi, M Sedraoui and M Bechouat. On-off control based particle swarm optimization for maximum power point tracking of wind turbine equipped by DFIG connected to the grid with energy storage. Int. J. Hydrogen Energ. 2015; 40, 13749-58.

[19] Y Dbaghi, S Farhat, M Mediouni, H Essakhi and A Elmoudden. Indirect power control of DFIG based on wind turbine operating in MPPT using backstepping approach. Int. J. Electr. Comput. Eng. $2021 ; 11,1951-61$.

[20] H Jenkal, B Bossoufi, A Boulezhar, A Lilane and S Hariss. Vector control of a doubly fed induction generator wind turbine. Mater. Today Proc. 2020; 30, 976-80.

[21] A Aarib, A EL Moudden, A EL Moudden and A Hmidat. Control and investigation of operational characteristics of variable speed wind turbines with doubly fed induction generators. Walailak J. Sci. \& Tech. 2021; 18, 10995.

[22] O Adekanle, M Guisser, E Abdelmounim and M Aboulfatah. Integral backstepping controller combined with high gain observer for the optimization of grid-connected doubly-fed induction generator. In: Proceedings of the 2017 International Conference on Wireless Technologies, Embedded and Intelligent Systems, Fez, Morocco. 2017, p. 1-7.

[23] ME Malah, A Ba-razzouk, E Abdelmounim and M Madark. Integral backstepping based nonlinear control for maximum power point tracking and unity power factor of a grid connected hybrid windphotovoltaic system. Indonesian J. Electr. Eng. Inform. 2020; 8, 706-22.

[24] K Khani and G Shahgholian. Analysis and optimization of frequency control in isolated microgrid with double-fed induction-generators based wind turbine. J. Int. Counc. Electr. Eng. 2019; 9, 24-37.

[25] R Laina, FE Lamzouri, E boufounas, AE Amrani and I Boumhidi. Intelligent control of a DFIG wind turbine using a PSO evolutionary algorithm. Proc. Comput. Sci. 2018; 127, 471-80.

[26] Y Chu and W Wang. PI controller design for DFIG wind power generation system RSC based on PSO algorithm. Appl. Mech. Mater. 2014; 508, 196-99.

[27] MM Alhato and S Bouallègue. Direct power control optimization for doubly fed induction generator basedwind turbine systems. Math. Comput. Appl. 2019; 24, 77.

[28] Z Chen, Z Lin, C Yue and Y Li. Particle swarm optimized command filtered backstepping control for an active magnetic bearing system. In: Proceedings of the 2018 IEEE International Conference on Information and Automation, Wuyishan, China. 2018, p. 155-60. 
[29] AO Salau, YW Gebru and D Bitew. Optimal network reconfiguration for power loss minimization and voltage profile enhancement in distribution systems. Heliyon 2020; 6, e04233.

[30] A Vincent and R Nersisson. Particle swarm optimization based PID controller tuning for level control of two tank system. IOP Conf. Ser. Mater. Sci. Eng. 2017; 263, 052001.

[31] H Dai, D Chen and Z Zheng. Effects of random values for particle swarm optimization algorithm. Algorithms 2018; 11, 23. 